\title{
New Names for Known Things: On the Association of Novel Word Forms with Existing Semantic Information
}

\author{
Christian Dobel, Markus Junghöfer, Caterina Breitenstein, \\ Benedikt Klauke, Stefan Knecht, Christo Pantev, \\ and Pienie Zwitserlood
}

\begin{abstract}
The plasticity of the adult memory network for integrating novel word forms (lexemes) was investigated with whole-head magnetoencephalography (MEG). We showed that spoken word forms of an (artificial) foreign language are integrated rapidly and successfully into existing lexical and conceptual memory networks. The new lexemes were learned in an untutored way, by pairing them frequently with one particular object (and thus meaning), and infrequently with 10 other objects (learned set). Other novel word forms were encountered just as often, but paired with many different objects (nonlearned set). Their impact on semantic memory was assessed with cross-modal priming, with novel word forms as primes and object pictures as targets. The MEG counterpart of the $\mathrm{N} 400(\mathrm{~N} 400 \mathrm{~m})$ served as an indicator of a semantic
\end{abstract}

\section{INTRODUCTION}

Children learn words and things they refer to more or less at the same time, with a rate of about 10 per day until puberty (Bloom, 2001). As a consequence, adults' brains store an extensive memory network of conceptual knowledge, which, for purposes of speaking and understanding, is hooked up to linguistic information-including the word class, gender, and word form (orthographic and phonological) associated with a particular concept. This linguistic information is stored in the "mental lexicon" that contains even for monolinguals some 50,000 entries (Levelt, 1989).

Even adults continue to learn new native-language words (such as "blog") for new concepts. Moreover, given that multilingualism is an increasingly important commodity in times of globalization, adults often learn new languages later in life. When acquiring a foreign language, ${ }^{1}$ adults learn new word forms (also called lexemes), and, if applicable, new syntactic information for conceptual knowledge already in situ. The strong correlation between language proficiency and academic or socioeconomic success in both native and nonnative speakers (Young et al., 2002; Greenberg, Macías, Rhodes, \& Chan, 2001; Kaestle, Campbell, Finn,

University of Münster (mis)match between words and pictures. Prior to learning, all novel words induced a pronounced N400m mismatch effect to the pictures. This component was strongly reduced after training for the learned novel lexemes only, and now closely resembled the brain's response to semantically related native-language words. This result cannot be explained by mere stimulus repetition or stimulus-stimulus association. Thus, learned novel words rapidly gained access to existing conceptual representations, as effectively as related native-language words. This association of novel lexemes and conceptual information happened fast and almost without effort. Neural networks mediating these integration processes were found within left temporal lobe, an area typically described as one of the main generators of the N400 response.

Johnson, \& Mikulecky, 2001) points to the urgency of developing efficient foreign-language acquisition programs.

An intriguing question is how lexemes of a new language become part of the vast existing memory networks of lexical and conceptual information. Also, it is still largely unresolved how this integration is neurophysiologically reflected in the brain (for overviews on neural organization and development of language, see Neville \& Bavelier, 1998; Nobre \& Plunkett, 1997). Despite their high relevance, such questions have long remained unexplored. Brain-imaging data from bilinguals who acquired a second language rather early in life (Perani et al., 1998, 2003) showed that comparable brain areas become activated by both languages in a verbal fluency task, and thus, "the bilingual brain cannot be viewed as the sum of two monolingual language systems" (Perani et al., 2003, p. 180). The pattern of activation varied individually and depended largely on L2 proficiency rather than on age of acquisition. Reviewing ERP studies, a similar conclusion was reached by Mueller, Hahne, Fujii, and Friederici (2005) suggesting "that lexical-semantic information processing in proficient L2 speakers and native speakers of a language are not qualitatively different" (p. 1230).

Although most studies investigated speakers that acquired two languages over the course of years, an important 
issue is whether such similarities in functional organization between the native and a later-acquired language are already present after a much shorter training period. There is recent behavioral evidence that new lexemes cause competition for existing word forms in the lexicon within very short time intervals, especially if this period includes a night's sleep (Dumay \& Gaskell, 2007; Gaskell \& Dumay, 2003; see De Diego Balaguer, Toro, RodriguezFornells, \& Bachoud-Levi, 2007, for a different method). With these fascinating findings, the authors showed that lexical effects come about rapidly, but they did not address how novel word forms become hooked up with semantic or conceptual information.

The later was shown behaviorally, with novel words producing facilitation to known concepts in a semantic task (Breitenstein et al., 2007) or interference in picture naming one week after learning (Clay, Bowers, Davis, \& Hanley, 2007), and with EEG, in a few longitudinal studies (Stein et al., 2006; McLaughlin, Osterhout, \& Kim, 2004). Stein et al. (2006), with a naturalistic learning situation, showed a latency modulation of the N400 for new words after 5 months of learning as compared to the same words before learning. The study by McLaughlin et al. (2004) assessed learning of French in a classroom situation. They showed a purely lexical effect, with a difference between French existing words and pseudowords at the level of the N400, after some $14 \mathrm{hr}$ of instruction. An additional semantic effect, that is, a reduced N400 due to semantic relatedness, needed more than $60 \mathrm{hr}$ of training, and became quite robust after about $140 \mathrm{hr}$ of instruction. This findings contrast with a recent study by Mestres-Missé, Rodriguez-Fornells, and Münte (2007), who had participants learn the meaning of novel words by embedding them in sentence contexts. After only three exposures, the N400 for the novel words almost looked like the N400 for native-language words. A consecutive priming test revealed semantic congruency effects for the novel words, be it with differences in latency and topography than for native-language words. How well these words were learned when tested explicitly, and with what level of retention, remains an open question (for functional neuroanatomy data of word learning from sentence context, see Mestres-Missé, Càmara, Rodriguez-Fornells, Rotte, \& Münte, 2008).

Clearly, these data show that far less than half a life is needed for novel lexemes to become integrated into lexical and conceptual memory. Our main issues here are whether this integration can be reached with little training time-compared to the longitudinal studies cited above - and with a procedure that does not require deep semantic processing. We therefore investigated foreignlanguage acquisition by means of untutored learning of novel word forms for existing concepts, using associative learning principles. Even without instruction, combining novel word forms with known concepts mimics foreignlanguage learning. As Clark (1988; see also Levelt, 1989) argues, due to the "principle of contrast," no real synonymy exists in any language. Thus, if a specific word expresses a specific notion, another word of the same language cannot correctly express the same notion. Therefore, a novel word combined with a known concept implies a novel language, even if the novel words largely share the phoneme inventory with the native language (as is the case in the study at hand, and for quite a few languages). We assessed the integration of novel word forms into existing neural networks of semantic memory with a cross-modal speech-to-concept priming paradigm. The underlying neurophysiological processes were explored by means of magnetoencephalography (MEG) and estimation of the underlying neural sources. Associative learning provides the advantages of low cognitive demands during training while yielding highly stable retention of a novel vocabulary (Breitenstein et al., 2004). The neural basis most likely consists of Hebbian cell assemblies, which become connected to sustain language processing (Pulvermüller, 1999). By systematic pairing of words and concepts, associative learning mimics how children and adults immersed in a foreign-language environment learn new word forms for concepts, which provides an ecological flavor to the learning paradigm.

The learning paradigm used is known as statistical or associative learning, and has been employed successfully before (see Breitenstein \& Knecht, 2002). Its design and testing is best illustrated by reference to our corresponding behavioral study, reported in Breitenstein et al. (2007). In a nutshell, spoken novel word forms are paired with object pictures, the statistical probability of particular pairings accumulating over time, in the course of 4 or 5 days of brief training sessions (about $20 \mathrm{~min}$ ). Participants decide "intuitively," whether novel words and objects fit together, but no feedback is given. The probability of particular pairings is manipulated between sets of novel word forms. In the learned set, each word form is paired 20 times with one specific object, and only twice with each of 10 different objects. The novel words from the nonlearned set were also heard 40 times each during training, but each time paired with a different object.

Novel word learning, assessed by the correctness of decisions during training, was very successful, increasing from chance level to almost 100\% correct on Day 5. Importantly, by the end of training, all participants translated the learned novel words into corresponding German words with almost perfect accuracy. This clearly shows that learning went beyond simple stimulus-stimulus association. Crossmodal semantic priming, before and after training, was used to assess the status of novel lexemes in the lexical/ conceptual network. Prior to training, semantic-decision latencies to pictures were equal when preceded by novel words and by unrelated German words. The novel word forms from the nonlearned set produced similar effects before and after training. Importantly, learned novel words had a decidedly different impact before and after training. They reliably facilitated picture processing after learning, to the same extent as semantically related native words. Thus, they behaved like existing, semantically related words 
after learning. We took this as evidence for their integration into existing conceptual and lexical memory.

So, at a behavioral level, new word forms learned with less than $2 \mathrm{hr}$ of exposure show effects close to those of native-language words. Although these findings are interesting by themselves, here, we focus on the neural correlates of such fast integration. There is very little evidence as to whether words of a novel language acquired within a brief period of training are neurophysiologically processed as native-language words, or whether they engage different processing systems. The few available studies showed differences, at the level of the $\mathrm{N} 400$, between native- and foreign-language words (Mestres-Missé et al., 2007; Alvarez, Holcomb, \& Grainger, 2003), or a differential impact of semantic and associative priming for unbalanced, but not for early, fluent bilinguals (Kotz \& Elston-Güttler, 2004; Kotz, 2001).

Note that most studies used words as targets, which allows for intralexical effects of association between nativeand foreign-language word forms. We opted for a combination of spoken (novel) word forms and pictures to assess lexical-conceptual integration using the $\mathrm{N} 400 \mathrm{~m}$ evoked response by whole-head MEG as a neurophysiological index of semantic integration, before and after training. In EEG, the N400 arises as a negative deflection, starting at around $300 \mathrm{msec}$, in response to the semantic goodnessof-fit between stimuli, such as words in sentences (Kutas \& Hillyard, 1980), real-word pairs (Van Petten, 1995), or pseudowords (Bentin, 1987). However, the N400 is also elicited by picture stimuli (Pratarelli, 1994), where it is attenuated as a function of semantic priming (Holcomb \& McPherson, 1994; Barrett \& Rugg, 1990).

The N400 component is often considered to reflect postlexical semantic integration processes (Chwilla, Brown, \& Hagoort, 1995; for recent reviews, see Van Petten \& Luka, 2006; Kutas \& Federmeier, 2000). For word stimuli, its amplitude is also sensitive to lexical factors, such as lexical status and word frequency (Van Petten, 1993). Therefore, Van Petten and Luka (2006) suggest that the N400 reflects concept retrieval rather than integration, and conclude, that the "... N400 amplitude is a general index of the ease or difficulty of retrieving stored conceptual knowledge associated with a word, which is dependent on both the stored representation itself, and the retrieval cues provided by the preceding context" (p. 281).

In our case, we assess the $\mathrm{N} 400$ during the processing of pictured objects, and evaluate the impact of the preceding context-consisting of novel or existing words-on picture processing. We consider the N400 as excellently suited to investigate the acquisition of novel lexemes because it allows us to observe these stimuli in action by assessing their impact on the processing of conceptual and semantic information provided by the pictured objects.

Much less is known about the N400m, the MEG counterpart of the N400 ERP component. It was found that the $\mathrm{N} 400 \mathrm{~m}$ is sensitive to the same violations as the N400 (e.g., Halgren et al., 2002; Helenius, Salmelin, Service, \& Connolly,
1998). Whole-head MEG and equivalent current dipole analysis, employed to narrow down the underlying neural generators of the component, revealed mixed results. However, there seems to be consensus on a stronger involvement of the left in comparison to the right hemisphere, especially for areas in or close to the temporal lobes (for recent reviews, see Van Petten \& Luka, 2006; Kwon et al., 2005; Halgren et al., 2002; Helenius et al., 1998, 2002; Mäkelä, Mäkinen, Nikkilä, Ilmoniemi, \& Tiitinen, 2001). In a recent study, Maess, Herrmann, Hahne, Nakamura, and Friederici (2006) revealed that the generators of the N400m involve temporal cortex and parts of frontal cortex. The activation of left frontal areas seems especially prominent when whole sentences are used.

We registered the evoked $\mathrm{N} 400 \mathrm{~m}$ response during the processing of pictured objects, preceded by auditory spoken word primes that were either the native-language name of the picture, native words semantically related to the picture, or novel lexemes from the learned and nonlearned conditions (see Figure 1A). The novel word forms consisted of the same as employed in Breitenstein et al. (2007). We hypothesized that all novel words should evoke a large $\mathrm{N} 400 \mathrm{~m}$ before learning and that this component should be strongly reduced after learning but for learned novel words only. A comparison of posttraining N400m effects of learned novel words, semantically related and identical words will reveal similarities and differences between novel and existing combinations of concepts and word forms.

\section{METHODS \\ Participants}

Twelve participants (mean age $=23$ years; right-handed native speakers of German with equal level of education) took part in the experiment. They all had normal hearing and normal or corrected-to-normal vision. None had participated in any of the earlier learning studies.

\section{Stimulus Material}

Ninety black and white object line drawings were taken from the Snodgrass and Vanderwart (1980) set. Half were man-made objects, the other half nature-made. In a first step, prime words were chosen from the Edinburgh Association Thesaurus (Kiss, Armstrong, Milroy, \& Piper, 1973) that were strongly semantically related to the corresponding object names. Twenty-two subjects subsequently rated the semantic closeness of the (German) words and their objects using a 7-point scale $(1=$ not related at all $; 7=$ strongly related). Forty-five words were selected to serve as primes in the semantically related condition, with a mean relatedness to their objects of $6.3(S D=0.2)$. Twenty wordobject combinations had a part-whole relationship (e.g., dog-paw), 25 combinations came from the same category 


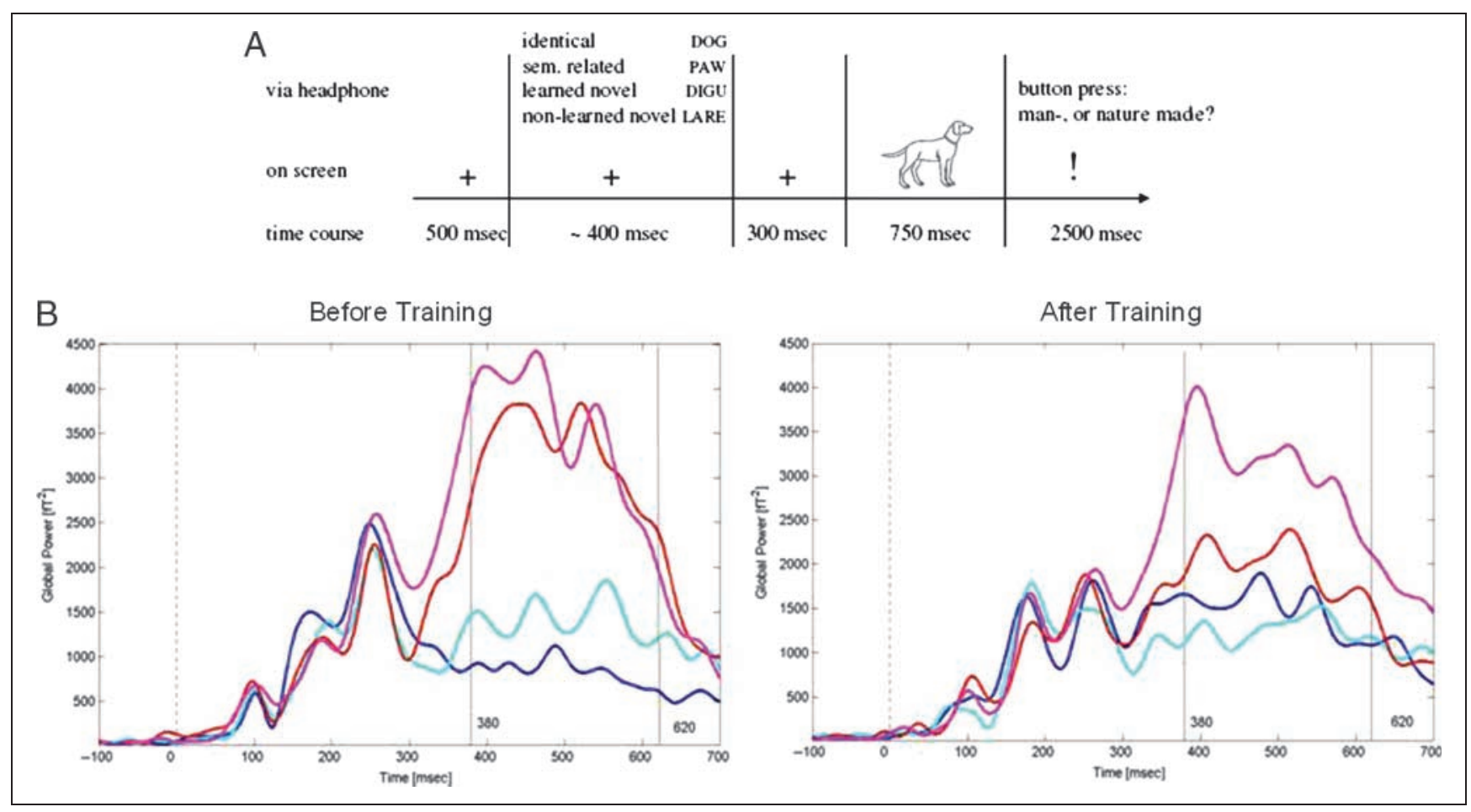

Figure 1. (A) Time course and conditions of the cross-modal semantic priming procedure. Note that the behavioral study (Breitenstein et al., 2007) also included an "unrelated" condition. (B) Global power plot across all sensors for all conditions before (left) and after (right) training. Dark blue: identical word; light blue: semantically related word; red: novel learned word; light red: novel unlearned word.

(e.g., cat-mouse). Care was taken that all combinations were response-congruent with respect to the man-made/ nature-made decision task (see below). The identical primes consisted of the German name for the same 45 objects.

Next, 90 novel word forms (e.g., binu, kage) were selected. These novel lexemes were all legal with respect to German phonotactics, and have been described in detail elsewhere (Breitenstein \& Knecht, 2002). All 180 stimuli were spoken by a female speaker, recorded digitally (Sony Minidisc Recorder MZ-NH900), and subsequently transformed to .wav files with Marc's HiMD Renderer. The stimuli were excised, at as close as possible to their onand offsets, with the software package Praat, and stored in individual sound files.

\section{Novel Word Training}

Participants were trained with the new vocabulary for less than 20 min a day, on 5 consecutive days. In the course of 5 days, the 45 novel words of the learned set were presented 40 times, 20 times with the identical object, but only twice with each of 10 different objects. The novel words of the nonlearned set were also presented 40 times, arbitrarily paired with objects, with each novel wordobject combination appearing only once. Note that the objects differed between the learned and nonlearned sets, and that all novel word forms and all objects appeared equally often during the training procedure. Participants learned according to one of two lists, with different novel word-object pairings, in order to avoid chance associations between specific stimuli.

On each learning trial, objects were presented $200 \mathrm{msec}$ after the onset of the auditory stimulus. Objects remained on the screen for $1500 \mathrm{msec}$, during which participants had to indicate via forced-choice button press whether words and objects matched. They were encouraged to do this on a spontaneously or on an intuitive basis. There was no feedback, and no information was given about the underlying learning principle.

A transfer test was applied on the last day to test the subjects' ability to translate the novel words into German. The test included all novel words from the learning and no-learning sets. The spoken German picture names were each paired with a novel word-the "correct one" in case of the learned set. Participants decided by button press whether pairings matched or not.

\section{MEG Cross-modal Priming Experiment: Pretraining and Posttraining}

In the course of the MEG priming experiments administered before and after training, each of the 45 objects from a participant's learned set was presented four times, preceded by four different auditory primes: (1) the German picture name, (2) the semantically related German word, (3) the novel lexeme from the learned set, and (4) a novel 
lexeme from the nonlearned set (see Figure 1A). Within participants, the materials were identical in the pre- and postexperiment. ${ }^{2}$ Primes were presented auditorily, followed after an interstimulus interval of $300 \mathrm{msec}$ by an object picture which was displayed for $750 \mathrm{msec}$. In order to avoid readiness fields as well as movement-related artifacts due to reaction preparation, a response delay was introduced: An exclamation mark presented for $2500 \mathrm{msec}$ after picture object offset signaled that participants should decide via button press whether the object was man-made or nature-made. Thus, decisions were made at leisure after appearance of the objects, which makes the latency data uninteresting. As a standard procedure to avoid confounds of priming effects due to response (in)congruency, existing words from the semantically related condition were always response-congruent with their target picture (both either denoting a man-made or a nature-made concept). The four primes for each target were presented in random order. A recording session lasted about $15 \mathrm{~min}$.

\section{MEG Recording and Data Analysis}

MEG signals were recorded by means of 275 sensors whole-head MEG system (Omega 275, CTF, VSM MedTech Ltd., Coquitlam, Canada) with first-order axial SQUID gradiometers $(2 \mathrm{~cm}$ diameter, $5 \mathrm{~cm}$ baseline, $2.2 \mathrm{~cm}$ average intersensor spacing). Data were recorded continuously with first-order gradient filtering at 274 sensors (one sensor turned off due to technical problems). Responses were sampled at $600 \mathrm{~Hz}$ and filtered on-line with a frequency band pass of 0-150 Hz. Recordings were further processed off-line using Brain Electrical Source Analysis (www.besa. de) as well as ElectroMagnetic EncephaloGraphy Software (www.emegs.org). Data were filtered using a 48-Hz lowpass and a $0.01-\mathrm{Hz}$ high-pass filter. The averaging epoch was defined from $300 \mathrm{msec}$ before picture onset to stimulus offset ( -300 to $750 \mathrm{msec}$ ) with a $150-\mathrm{msec}$ prestimulus baseline. Individual averages were standardized on the mean MEG sensor configuration across all participants and runs, and thus, corrected for differing head positions of the participants within the MEG scanner (Junghöfer, Peyk, Flaisch, \& Schupp, 2006).

As the amplitudes of the measured fields heavily depend on participants' head size, individual averages were normalized based on the individual root-mean-square (RMS; the square-root of the mean across the squared amplitudes of all sensors) amplitudes for the time interval of the N400m. More specifically, the maxima of the RMS amplitudes were averaged across all conditions for each participant. These individual means were divided by the overall mean RMS maxima across all subjects, resulting in an individual factor for each participant that describes the deviation from the group average. These individual factors served to normalize the participant's averaged data and to correct for differential influences of individual head sizes. The global power (the mean across the squared field amplitudes of all sensors) across subjects separated for all conditions before and after training served to get an impression of the time course of activity within sensor space. Magnetic field-strengths of every sensor and each time point were analyzed with a point-wise ANOVA from picture onset to $700 \mathrm{msec}$ after. A significant, long-lasting interaction of session (pre vs. post learning) and prime type (German picture name, semantically related word, learned novel word, nonlearned novel word) was found between 380 and $620 \mathrm{msec}$ after object onset, which was established as interval for the N400m in sensor space. Within this critical interval, the global power, calculated separately for sensors of the left and right hemispheres, was analyzed with a repeated measures ANOVA with the factors session, prime type, and hemisphere.

To evaluate the underlying neural network activity, source-space activity was estimated using the L2-MinimumNorm-Least Squares method (L2-MNLS; Hämäläinen \& Ilmoniemi, 1994). The corresponding L2-MNLS amplitudes were analyzed with a point-wise repeated measures ANOVA, with the factors session and prime type. MNLS activities were grouped into homologous regions of interest of both hemispheres if they consistently displayed significant interactions $(p<.01)$ of session and prime type for at least $100 \mathrm{msec}$. This determined the critical time interval for the N400m in source space (400-540 msec). These values were used for statistical analyses with a repeated measures ANOVA with the factors session, prime type, and hemisphere. $t$ Tests were used for post hoc comparisons.

The statistical parametric $F$ values of the interaction Session $\times$ Prime type were mapped on a standard cortical surface in order to display the origin of effects in more detail. This type of analysis for multichannel recordings (EEG and MEG) has become an established procedure for sensor and source space (for recent studies, see e.g., Dobel, Pusche, Zwitserlood, \& Junghöfer, 2008; Kissler, Herbert, Peyk, \& Junghöfer, 2007; Schupp et al., 2007).

\section{RESULTS \\ Behavioral Data}

During the course of training, correct responses (hits and correct rejections) progressed linearly from chance level of $53 \%$ on Day 1 to $93 \%$ on Day $5[F(4,11)=293.74, p<$ $.001]$. Planned contrasts suggest that this is due to a linear effect $[F(1,11)=725, p<.001]$. A significant, but much smaller, quadratic effect $[F(1,11)=56.23, p<$ $.001]$ was also visible due to the asymptotic slope of typical learning curves. Learning happened very rapidly, as evidenced by a correct mean response rate of $85 \%$ on Day 3. Participants also showed clear transfer effects, with over $90 \%$ correct answers on Day 5 in the translation test (mean $=95.3, S D=6.7)$. Because of the introduced response delay during the MEG sessions, reaction times from the pre- and postlearning priming experiments were not 
analyzed. The error percentages were low (3-5\%) and unaffected by conditions.

\section{MEG Data}

The global power plots in source space for the four prime types, with pre- and posttraining sessions displayed separately, illustrate an interaction of session and prime type (see Figure 1B). ${ }^{3}$ Before training, and as predicted, semantically related primes and identical object names yielded a small N400m but both sets of novel primes evoked pronounced $\mathrm{N} 400 \mathrm{~m}$ responses to the target pictures reflecting the typical semantic/identity priming effect (cf. Pratarelli, 1994). This interaction clearly changed after learning: Now only the nonlearned words still induced a strong N400m response, whereas the by-now truly learned novel words revealed a much weaker N400m response upon object presentation. In fact, after learning, the effect of learned novel word forms on the N400m to their objects was similar to the $\mathrm{N} 400 \mathrm{~m}$ effects of identical and semantically related words.

This descriptive analysis was confirmed by statistical analyses in sensor and source space. Analyses of evoked responses in sensor space within the critical time interval revealed a significant three-way interaction of session, prime type, and hemisphere $[F(3,33)=3.44, p=.028$; Greenhouse-Geisser corrected: $p=.034]$. Post hoc analyses revealed clear effects originating in the left hemisphere [the interaction of session and prime type was reliable only for the left hemisphere: $F(3,33)=3.4, p=.03$; Greenhouse-Geisser corrected: $p=.04]$. Prior to training, priming by both types of novel words induced the same N400m pattern to the target pictures, but both evoked higher activity than the German word primes: the learned set differed before learning from both identical $[t(11)=$ $3.41, p=.006]$ and semantically related German word $[t(11)=3.85, p=.003]$. After training, nonlearned novel words still evoked a strong $\mathrm{N} 400 \mathrm{~m}$ response to the pictures, but the learned novel words did not. Although learned novel words still differed from identical native words in their impact on the $\mathrm{N} 400 \mathrm{~m}$ for picture processing $[t(11)=2.4, p=.04]$, the difference was much smaller than in the presession. On the postsession, learned words did not differ any longer from semantically related words $[t(11)=1.47, n s]$. In other words, the only condition that displayed an attenuation before and after learning was the $\mathrm{N} 400 \mathrm{~m}$ for targets paired with learned novel words $[t(11)=3.32, p=.007]$. All other comparisons between sessions were not significant (all $t<1.2$; all $p>.24$ ).

For the right hemisphere, there were no significant differences between prime types before and after training [the interaction of session and prime type for the right hemisphere: $F(3,33)=0.5, n s]$; none of the post hoc comparisons was significant (all $t<1$; all $p>$.33).

The statistical results were almost identical for the analyses with L2-MNLS estimates in source space as an index of the underlying neural activity. Again, the estimated neural activity demonstrated a significant three-way interaction of session, prime type, and hemisphere $[F(3$, $33)=3.23, p=.035$; Greenhouse-Geisser corrected: $p=.071]$. These effects originated in the left hemisphere [the interaction of session and prime type was significant only for the left hemisphere: $F(3,33)=7.96, p<.001$; Greenhouse-Geisser corrected: $p=.002]$. Before learning, the learned condition displayed a higher $\mathrm{N} 400 \mathrm{~m}$ response than both German conditions [for identical German words: $t(11)=5.9, p<.001$; for semantically related: $t(11)=4.5$, $p=.001]$. After learning, these differences disappeared (both $t<1.8$; both $p>1$ ). As in the sensor space, the only condition that showed a reduced activity from preto postlearning was the brain response to picture targets primed by learned novel words $[t(11)=3.69, p=.004]$. All other conditions were not significantly different before and after learning (all $t<2$; all $p \geq .08$ ). Again, no significant differences between prime types before and after training were found for the right hemisphere [the interaction of session and prime type: $F(3,33)=0.94, n s]$; all post hoc comparisons were not significant.

As shown in Figure 1B and the top of Figure 2, nonlearned novel words showed a trend toward a reduction from pre- to postsession, which almost reached significance $(p=.08)$. To investigate the contribution of this difference to the three-way interaction reported above, we calculated an additional repeated measures ANOVA, with only two levels of the factor prime type (learned novel word, nonlearned novel word). The three-way interaction of session, prime type, and hemisphere remained significant $[F(1,11)=5.4, p=.04]$. Thus, the reduction of the $\mathrm{N} 400 \mathrm{~m}$ from pre- to postsession is larger for learned and nonlearned novel words, and the effect of learned novel words cannot be reduced to mere repetition effects. ${ }^{4}$

In short, the only $\mathrm{N} 400 \mathrm{~m}$ response that reliably changed as a function of training was the response to pictures primed by learned novel words, and this change was evident in the left hemisphere only. Mapping the $F$ values for the interaction of session and prime type of the point-wise ANOVA in source space located the observed effects in the area of the left temporal lobe (see Figure 2, bottom).

\section{DISCUSSION}

We investigated the neural correlates of the rapid acquisition of novel word forms by means of associative learning, during the course of 5 days, but with only about $1.5 \mathrm{hr}$ exposure overall. After the last learning session, participants displayed almost perfect performance in matching learned novel lexemes and corresponding objects. In fact, they were very good already at Day 3, after $1 \mathrm{hr}$ of learning. A transfer test demonstrated that this was not the result of a mere stimulus-stimulus pairing. In Breitenstein et al. (2007), we demonstrated at the behavioral level how learning resulted in fast acquisition of novel words so that former pseudowords behaved like words from 

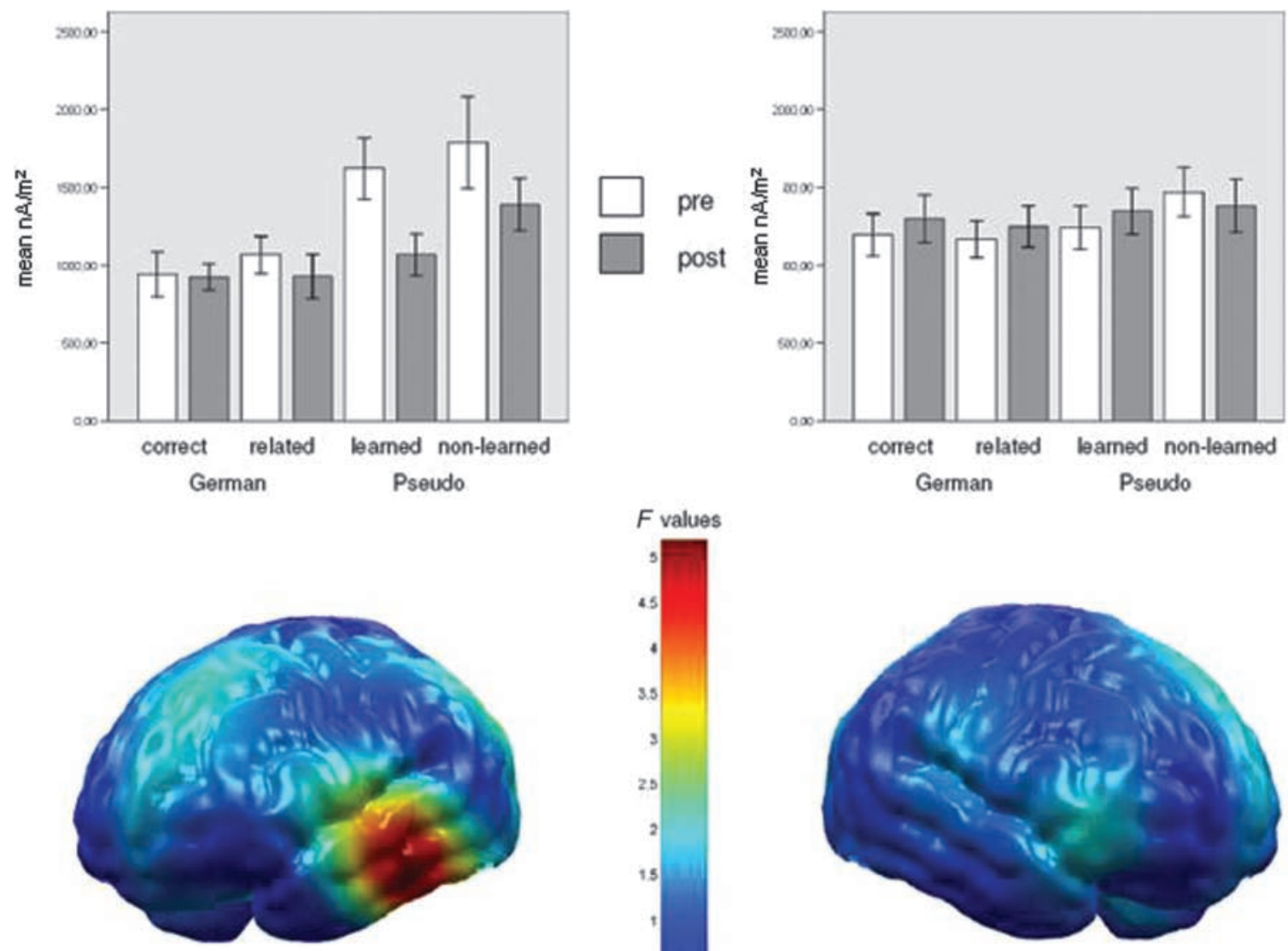

left hemisphere
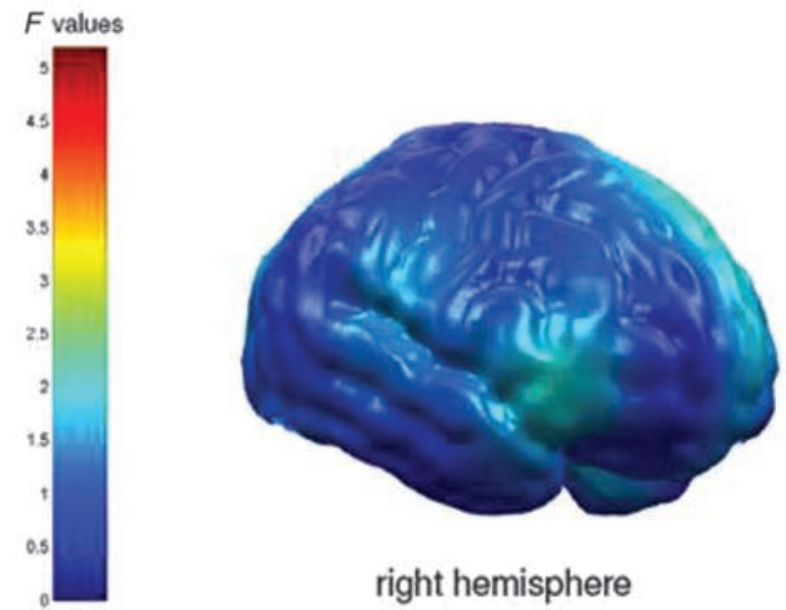

right hemisphere

Figure 2. Minimum-norm least square (MNLS) estimations for the N400m were grouped if they consistently displayed highly significant interactions of session and prime type within the interval of $400-540 \mathrm{msec}$. Top of figure displays MNLS values over both temporal areas, broken down by prime type (pretraining: white; posttraining: gray; error bars denote standard errors). Bottom of figure displays the statistical parametric $F$ values of the interaction Session $\times$ Prime Type, mapped on a standard cortical surface. Note that colors representing $F$ values above 3 correspond to a $p$ value smaller than .07 . The interaction of session and word type can be clearly seen over left temporal gyrus.

one's native language. Here, we clearly go beyond this by showing that such newly acquired lexemes evoke neurophysiological responses that are almost indistinguishable from those for words from the native language. Before learning, all novel words induced a strong N400m response to subsequently processed pictures of objects, indexing a semantic mismatch between word and picture. After learning, only the nonlearned novel words maintained such a strong evoked response. The response to learned novel words closely resembled those induced by native-language object names, or words from the object's conceptual domain.

Thus, after less than $2 \mathrm{hr}$ of learning, previously novel word forms seem to acquire a lexical status that allows an efficient and fast connection to conceptual memory networks. This clearly demonstrates the plasticity of the adult brain for learning new lexemes, and their integration into the lexical system - as already shown by Dumay and Gaskell (2007) and Gaskell and Dumay (2003). In addition, we show that such lexemes are linked to conceptualsemantic memory networks. Training on five consecutive days crucially allows for consolidation and transfer from hippocampal information to relevant areas in neocortexleft middle temporal cortex, in our case (cf. Dumay \& Gaskell, 2007).

Interestingly, there was a very robust $\mathrm{N} 400 \mathrm{~m}$ in the first session for objects primed by novel (pseudo-)words. Apparently, participants tried to derive meaning from stimuli that were never encountered previously, and even though their task did not necessitate this. Thus, there seems to be some automatic, on-the-fly integration of meaning, even though not warranted by earlier experience (cf. Chwilla, Kolk, \& Vissers, 2007).

We also observed a reduction in $\mathrm{N} 400 \mathrm{~m}$ amplitude over sessions for the nonlearned novel word condition which, however, failed to reach significance. A reduction of the N400 amplitude due to repetition for pseudowords and real words has been reported previously (Olichney et al., 2006; Deacon, Dynowska, Ritter, \& Grose-Fifer, 2004). Note that the nonlearned novel words must have become quite familiar, having been heard more than 40 times from pre- to posttest. The slight reduction of the N400m 
amplitude of unlearned novel words is compatible with the observation by Gaskell and Dumay (2003) that repeated exposure to novel word forms creates a lexical entry. For the novel words of the nonlearned set, such an entry cannot be strongly connected to any semantic-memory representation. At present, we cannot differentiate between effects of mere repetition of novel words on picture processing and repetition in combination with randomly associated objects that might provide at least some semantic content.

Learning is accomplished much faster and by different training means and settings than in Clay et al. (2007) and in the N400 study by McLaughlin et al. (2004), where novel words were trained in regular classroom settings. After more than $60 \mathrm{hr}$ of language exposure, N400 measures started to show sensitivity to the semantic relationship between newly learned French words. Of course, their learners had a tough time because the semantic relation between pairs of new words was tested. McLaughlin et al. do not report how often their learners had encountered the critical words during their classroom hours. In the study at hand, learned novel words were encountered 40 times and only half of the times with the intended target object. Apparently, due to this frequent coupling with the same object, the link between the novel lexemes and the conceptual information about this object starts to emerge from the noise of random alternative couplings. Because we measured comprehension of the newly acquired word forms more directly in the transfer test (and for additional reasons mentioned below), we feel safe to say that through associative learning, these word forms become integrated into existing lexical and conceptual memory over the course of a few days.

The critical question is, thus, whether we investigated "language training," "memory training," or mere stimulusstimulus association. In our opinion, there are two ways to deal with this question. First, we can challenge the question itself. There is increasing evidence for strong relationships between word and object recognition systems (Vandenberghe, Price, Wise, Josephs, \& Frackowiak, 1996), and thus, it was argued "... against the isolation of language from other cognitive systems with which it may share properties" (Nobre \& Plunkett, 1997, p. 263). In fact, we doubt that there are types of learning that apply specifically to only one domain. Secondly, there are two pieces of evidence that cast doubt on an interpretation of mere stimulus-stimulus association. As mentioned earlier, the high performance in the transfer test showed that our learning procedure went beyond mere associations, allowing a direct translation of novel word forms into native-language words, even though this association was not explicitly trained. Moreover, in an experiment on action verb learning, we used the same learning procedure but with many different pictures of the same underlying action (with different actors, as well as different settings and environments) and the data of this study fully replicate the results reported here (Enriquez-Geppert, Zwitserlood,
Junghöfer, \& Dobel, 2007). Finally, recent data and modeling by Yu and Smith (2007) and Yu, Smith, Klein, and Shiffrin (2007) cast doubt on the viability of the traditional distinctions between different types of learning (from hypothesis testing to smart and to dumb associative learning). In essence, their suggestion is that these learning mechanisms may be fundamentally (and formally) the same.

How fast is this learning? As argued above in more detail, we assume that associative learning is a faster and more effective method than regular classroom training. However, there are data demonstrating even faster effects. First, Dumay and Gaskell (2007) showed that novel word forms exhibit lexical competition effects after no more than $12 \mathrm{hr}$, with an intervening consolidation period of sleep. Note that these competition effects are purely lexical because their novel word forms were not associated with meaning. Second, Mestres-Missé et al. (2007) found almost immediate effects during learning, in terms of a reduced N400 on repetition of novel word forms presented in context. They also observed a semantic effect in terms of priming, when the novel lexeme is followed by its nativelanguage (Spanish) counterpart. Given that the evoked responses for semantic priming within the native language were quite different from those for novel words priming their Spanish counterpart, Mestres-Missé et al. believe that they are tapping into still rather weak lexical associations, not into associations between the novel lexeme and the concept. They thus conclude that "It remains to be shown whether consolidation of the novel words via further practice and use in multiple contexts and the resulting direct access of the novel word to its concept would abolish the brain-potential differences between novel and real words" (Mestres-Missé et al., 2007, pp. 1863-1864). Given that our N400 priming effects on the semantic processing of pictured objects are statistically the same for native and novel words, we believe that our data actually capture this situation in which a stable link between the novel lexeme and conceptual information is established.

The brain region with strongest effects sizes for the integration of novel words into networks already in situ seems to be the left temporal lobe. We reached this result by a completely data-driven way of analysis, but it confirms earlier studies: "Overall, the neuropsychological, intracranial, and MEG results converge to suggest that a large portion of the temporal lobes are responsible for the scalp-recorded N400 component, but that the left hemisphere makes a larger contribution than the right" (Van Petten \& Luka, 2006, p. 286). However, this does not imply that the left temporal lobe is the sole generator of the $\mathrm{N} 400(\mathrm{~m})$ response. Future measures with more participants, and thus, better signal-to-noise ratio might reveal the participation of further areas within an assumed distributed neural network of frontal, parietal, and temporal regions. In fact, especially the use of semantically and/or syntactically violated sentences (e.g., Maess et al., 2006; Friederici, Rüschemeyer, Hahne, \& Fiebach, 2003; Halgren et al., 2002) evoked widespread 
frontal and temporal activity, but again predominantly in regions of the left hemisphere. Second, the visual modality of the target stimulus material might have contributed to the N400 hemisphere effect, as stronger leftlateralization for visually compared to auditory presented words has been reported (Marinkovic et al., 2003), In sum, our data-driven approach underscored the involvement of left temporal regions in associating word forms with meaning, and thus, in areas that have already been identified by a large number of studies using different methodologies and paradigms.

The middle temporal gyrus had been identified before as being part of a "common semantic system" (Vandenberghe et al., 1996), emphasizing its involvement in supramodal semantic processing (Price, 2000). Vandenberghe et al. (1996) assumed that the common semantic system developed phylogenetically when primates first learned to process language by adapting the existing object-recognition system to combine meaning and sounds of words. We demonstrated here on a much smaller time scale that this region is crucially involved when humans learn to attribute meaning to novel words in an impoverished environment. Others also stressed the importance of this region for lexical-semantic processing (Poeppel et al., 2004; Lee, Robbins, Graham, \& Owen, 2002; Wise et al., 2001; Demonet, Price, Wise, \& Frackowiak, 1994) as well as for good memory retention. A recent PET study (Raboyeau et al., 2004), with French participants who had studied English words over the course of 4 weeks, showed that left middle temporal cortex was activated after learning, mainly in participants who remembered studied items well.

Given that primes and targets were response-congruent, our results might have been influenced by attentional and strategic task factors-although there is evidence that semantic effects cannot be reduced to response congruency (Bueno \& Frenck-Mestres, 2008). The time course of the investigated component, the conditions under which it arose, the occipito-temporal generators, and its left-hemispheric dominance all imply that it is, in fact, an N400m. Nevertheless, there are components in this time interval that are related to attention and conscious recollection such as the late positive potential (LPP; e.g., Picton, 1992; Johnson, 1988). The LPP has, however, a different signature (e.g., Herbert, Junghöfer, \& Kissler, 2008) and responds differently to experimental manipulations. For instance, Misra and Holcomb (2003) demonstrated an attenuation of the N400 upon target words even when primes were presented subliminally. In contrast, the LPP seems to depend on conscious recollection of primes. Although we cannot exclude that attentional processes influenced our results, they would not change our conclusions regarding the effects of novel word learning on evoked late potentials and fields. We see it as a challenge for future studies to demonstrate that learned novel words can produce priming effects on subsequent targets even if primes appear below conscious awareness. In our opinion, such a finding would constitute an ultimate test to prove that novel words are, in fact, as deeply integrated in existing language networks as one's native vocabulary.

Summing up, our findings provide firm evidence that few hours of associative learning, with intervening periods of sleep, are sufficient to yield comprehensive lexical status and linkage to the conceptual memory network for previously novel lexemes. This was accomplished very fast and without tutored input. Thus, word forms learned by simple means in impoverished environments become rapidly integrated into existing networks of lexical and conceptual memory. Behavioral and neurophysiologic responses to these newly acquired words were indistinguishable from responses to words of one's native language, speaking against the hypothesis of special and more effortful neural network processing of second-language contents. Thus, even for adults, efficient learning of new vocabulary is not necessarily a laborious and effortful process. This again demonstrates a substantial plasticity of the mature brain for learning and integrating new word forms in a fast and effortless way.

\section{Acknowledgments}

Research was supported by the VW Stiftung (Az.: I/80 708) and the German Ministry of Education and Research (BMBF: 01GW0520). We thank Jens Bölte, Andreas Wollbrink, Dirk Vorberg, and two anonymous reviewers for their valuable support, encouragement, and comments on earlier versions of the manuscript.

Reprint requests should be sent to Christian Dobel, Institut für Biomagnetismus und Biosignalanalyse, Malmedyweg 15, 48149 Münster, Germany, or via e-mail: cdobel@uni-muenster.de.

\section{Notes}

1. Given that all of our subjects know more than one language, next to the native language (L1), we prefer to use "foreign language" (FL) to the more common "second language" (L2).

2. We included a semantically unrelated condition in the study by Breitenstein et al. (2007). Because the results were very similar to the novel nonlearned condition, and for reasons of parsimony, it was left out here.

3. No significant effects of prime type were found in earlier time windows (M100, M170, and M250).

4. We thank an anonymous reviewer for pointing out this option.

\section{REFERENCES}

Alvarez, R. P., Holcomb, P. J., \& Grainger, J. (2003). Accessing word meaning in two languages: An event-related brain potential study of beginning bilinguals. Brain and Language, 87, 290-304.

Barrett, S. E., \& Rugg, M. D. (1990). Event-related potentials and the semantic matching of pictures. Brain and Cognition, 14, 201-212.

Bentin, S. (1987). Event-related potentials, semantic processing and expectancy factors in word recognition. Brain and Language, 31, 308-327.

Bloom, P. (2001). Précis of how children learn the meaning of words. Behavioral and Brain Sciences, 24, 1095-1103.

Breitenstein, C., \& Knecht, S. (2002). Development and validation of a language learning model for behavioral 
and functional-imaging studies. Journal of Neuroscience Methods, 114, 173-179.

Breitenstein, C., Wailke, S., Bushuven, S., Kamping, S., Zwitserlood, P., Ringelstein, E. B., et al. (2004).

D-Amphetamine boosts language learning independent of its cardiovascular and motor arousing effects. Neuropsychopharmacology, 29, 1704-1714.

Breitenstein, C., Zwitserlood, P., de Vries, M. H., Feldhuis, C., Knecht, S., \& Dobel, C. (2007). Five days versus a lifetime: Intense associative vocabulary training generates lexically integrated words. Restorative Neurology and Neuroscience, 25, 493-500.

Bueno, S., \& Frenck-Mestres, C. (2008). The activation of semantic memory: Effects of primes exposure, prime-target relationship and task demands. Memory \& Cognition, 36, 882-898.

Chwilla, D. J., Brown, C. M., \& Hagoort, P. (1995). The N400 as a function of the level of processing. Psychophysiology, 32, 274-285.

Chwilla, D. J., Kolk, H. J., \& Vissers, C. T. W. M. (2007). Immediate integration of novel meanings: N400 support for an embodied view of language comprehension. Brain Research, 1183, 109-123.

Clark, E. V. (1988). On the logic of contrast. Journal of Child Language, 15, 317-335.

Clay, F., Bowers, J. S., Davis, C., \& Hanley, D. A. (2007). Teaching adults new words: The role of practice and consolidation. Journal of Experimental Psychology: Learning, Memory, and Cognition, 33, 970-976.

De Diego Balaguer, R., Toro, J. M., Rodriguez-Fornells, A., \& Bachoud-Levi, A. V. (2007). Different neurophysiological mechanisms underlying word and rule extraction from speech. PLOS ONE, 11, 1-11.

Deacon, D., Dynowska, A., Ritter, W., \& Grose-Fifer, J. (2004). Repetition and semantic priming of nonwords: Implications for theories of $\mathrm{N} 400$ and word recognition. Psychophysiology, 41, 60-74.

Demonet, J. F., Price, C., Wise, R., \& Frackowiak, R. S. (1994). Differential activation of right and left posterior sylvian regions by semantic and phonological tasks: A positron-emission tomography study in normal human subjects. Neuroscience Letters, 182, 25-28.

Dobel, C., Pusche, C., Zwitserlood, P., \& Junghöfer, M. (2008). Early left-hemispheric dysfunction of face processing in congenital prosopagnosia: An MEG study. PLOS ONE, 3, e2326.

Dumay, N., \& Gaskell, M. G. (2007). Sleep-associated changes in the mental representation of spoken words. Psychological Science, 18, 35-39.

Enriquez-Geppert, S., Zwitserlood, P., Junghöfer, M., \& Dobel, C. (2007). MEG as a measure of neural plasticity in verb learning. Cognitive Neuroscience Annual Meeting Program, 252.

Friederici, A. D., Rüschemeyer, S. A., Hahne, A., \& Fiebach, C. J. (2003). The role of left inferior frontal and superior temporal cortex in sentence comprehension: Localizing syntactic and semantic processes. Cerebral Cortex, 41, 60-74.

Gaskell, M. G., \& Dumay, N. (2003). Lexical competition and the acquisition of novel words. Cognition, 89, 105-132.

Greenberg, E., Macías, R. F., Rhodes, D., \& Chan, T. (2001). English literacy and language minorities in the United States (Rep. No. NCES 2001-464). Washington, DC: U.S. Department of Education, National Center for Education Statistics.

Halgren, E., Dhond, R., Christensen, N., Van Petten, C., Marinkovic, K., Lewine, J., et al. (2002). N400-like MEG responses modulated by semantic context, word frequency, and lexical class in sentences. Neuroimage, 17, 1101-1116.
Hämäläinen, M. S., \& Ilmoniemi, R. J. (1994). Interpreting magnetic fields of the brain: Minimum-norm estimates. Medical E Biological Engineering E Computing, 32, 35-42.

Helenius, P., Salmelin, R., Service, E., \& Connolly, J. (1998). Distinct time courses of word and context comprehension in the left temporal cortex. Brain, 121, 1133-1142.

Helenius, P., Salmelin, R., Service, E., Connolly, J., Leinonen, S., \& Lyytinen, H. (2002). Cortical activation during spoken-word segmentation in nonreading-impaired and dyslexic adults. Journal of Neuroscience, 22, 2936-2944.

Herbert, C., Junghöfer, M., \& Kissler, J. (2008). Event related potentials to emotional adjectives during reading. Psychophysiology, 45, 487-498.

Holcomb, P. J., \& McPherson, W. B. (1994). Event-related brain potentials reflect semantic priming effects in an object decision task. Brain and Cognition, 24, 259-276.

Johnson, R., Jr. (1988). The amplitude of the P300 component of the event-related potential: Review and synthesis. In P. K. Ackles, J. R. Jennings, \& M. G. H. Coles (Eds.), Advances in psychophysiology (Vol. 3, pp. 69-138). Greenwich, CT: JAI Press.

Junghöfer, M., Peyk, P., Flaisch, T., \& Schupp, H. (2006). Chapter 7: Neuroimaging methods in affective neuroscience: Selected methodological issues. In S. Anders, G. Ende, M. Junghöfer, J. Kissler, \& D. Wildgruber (Eds.), Understanding emotions. Progress in brain research (Vol. 156, pp. 123-143). Oxford, UK: Elsevier.

Kaestle, C. F., Campbell, A., Finn, J. D., Johnson, S. T., \& Mikulecky, L. J. (2001). Adult literacy and education in America-Four studies based on the National Adult Literacy Survey (Rep. No. NCES 2001-534). Washington, DC: U.S. Department of Education, National Center for Education Statistics.

Kiss, G. R., Armstrong, C., Milroy, R., \& Piper, J. (1973). An associative thesaurus of English and its computer analysis. In A. J. Aitken, R. W. Bailey, \& N. Hamilton-Smith (Eds.), The computer and literary studies (pp. 153-165). Edinburgh: Edinburgh University Press.

Kissler, J., Herbert, C., Peyk, P., \& Junghöfer, M. (2007). "Buzzwords"-Early cortical responses to emotional words. Psychological Science, 18, 475-480.

Kotz, S. A. (2001). Neurolinguistic evidence for bilingual language representation: A comparison of reaction times and event-related brain potentials. Bilingualism: Language and Cognition, 4, 143-154.

Kotz, S. A., \& Elston-Güttler, K. (2004). The role of proficiency on processing categorical and associative information in the L2 as revealed by reaction times and event-related brain potentials. Journal of Neurolinguistics, 17, 215-235.

Kutas, M., \& Federmeier, K. (2000). Electrophysiology reveals semantic memory use in language comprehension. Trends in Cognitive Sciences, 4, 463-470.

Kutas, M., \& Hillyard, S. A. (1980). Reading senseless sentences: Brain potentials reflect semantic incongruity. Science, 207, 203-205.

Kwon, H., Kuriki, S., Kim, J. M., Lee, Y. H., Kim, K., \& Nam, K. (2005). MEG study on neural activities associated with syntactic and semantic violations in spoken Korean sentences. Neuroscience Research, 51, 349-357.

Lee, A. C., Robbins, T. W., Graham, K. S., \& Owen, A. M. (2002). "Prey or pray?" Semantic memory investigated using a novel episodic memory task. Neuroimage, 16, 724-735.

Levelt, W. J. M. (1989). Speaking: From intention to articulation. Cambridge, MA: MIT Press.

Maess, B., Herrmann, C. S., Hahne, A., Nakamura, A., \& Friederici, A. D. (2006). Localizing the distributed language network responsible for the N400 measured by MEG during auditory sentence processing. Brain Research, 1096, 163-172. 
Mäkelä, A., Mäkinen, V., Nikkilä, M., Ilmoniemi, R., \& Tiitinen, H. (2001). Magnetoencephalographic (MEG) localization of the auditory N400m: Effects of stimulus duration. NeuroReport, 11, 249-253.

Marinkovic, K., Dhond, R. P., Dale, A. M., Glessner, M., Carr, A. \& Halgren, E. (2003). Spatiotemporal dynamics of modality specific and supramodal word processing. Neuron, 38, 487-497.

McLaughlin, J., Osterhout, L., \& Kim, A. (2004). Neural correlates of second-language word learning: Minimal instruction produces rapid change. Nature Neuroscience, 7, 703-704.

Mestres-Missé, A., Càmara, E., Rodriguez-Fornells, A., Rotte, M., \& Münte, T. F. (2008). Functional neuroanatomy of meaning acquisition from context. Journal of Cognitive Neuroscience, 20, 2153-2166.

Mestres-Missé, A., Rodriguez-Fornells, A., \& Münte, T. F. (2007). Watching the brain during meaning acquisition. Cerebral Cortex, 17, 1858-1866.

Misra, M., \& Holcomb, P. J. (2003). Event-related potential indices of masked repetition priming. Psychophysiology, 40, 115-130.

Mueller, J. L., Hahne, A., Fujii, Y., \& Friederici, A. D. (2005). Native and nonnative speakers' processing of a miniature version of Japanese as revealed by ERPs. Journal of Cognitive Neuroscience, 17, 1229-1244.

Neville, H. J., \& Bavelier, D. (1998). Neural organization and plasticity of language. Current Opinion in Biology, 8, 254-258.

Nobre, A. C., \& Plunkett, K. (1997). The neural system of language: Structure and development. Current Opinion in Biology, 7, 262-268.

Olichney, J. M., Iragui, V. J., Salmon, D. P., Riggins, B. R., Morris, S. K., \& Kutas, M. (2006). Absent event-related potential (ERP) word repetition effects in mild Alzheimer's disease. Clinical Neurophysiology, 117, 1319-1330.

Perani, D., Abutalebi, J., Paulesu, E., Brambati, S., Scifo, P., Cappa, S. F., et al. (2003). The role of age of acquisition and language usage in early, high proficient bilinguals: An fMRI study during verbal fluency. Human Brain Mapping, 19, 170-182.

Perani, D., Paulesu, E., Galles, N. S., Dupoux, E., Dehaene, S., Bettinardi, V., et al. (1998). The bilingual brain: Proficiency and age of acquisition of the second language. Brain, 121, 1841-1852.

Picton, T. W. (1992). The P300 wave of the human event-related potential. Journal of Clinical Neurophysiology, 9, 456-479.

Poeppel, D., Guillemin, A., Thompson, J., Fritz, J., Bavelier, D., \& Braun, A. R. (2004). Auditory lexical decision, categorical perception, and FM direction discrimination differentially engage left and right auditory cortex. Neuropsychologia, 42, $183-200$.
Pratarelli, M. E. (1994). Semantic processing of pictures and spoken words: Evidence from event related potentials. Brain and Cognition, 24, 137-157.

Price, C. J. (2000). The anatomy of language: Contributions from functional neuroimaging. Journal of Anatomy, 197, 335-359.

Pulvermüller, F. (1999). Words in the brain's language. Behavioral and Brain Sciences, 22, 252-336.

Raboyeau, G., Marie, N., Balduyck, S., Gros, H., Démonet, J.-F., \& Cardebat, D. (2004). Lexical learning of the English language: A PET study in healthy French subjects. Neuroimage, 22, 1808-1818.

Schupp, H. T., Stockburger, J., Codispoti, M., Junghöfer, M., Weike, A. I., \& Hamm, A. O. (2007). Selective visual attention to emotion. Journal of Neuroscience, 27, 1082-1089.

Snodgrass, J. G., \& Vanderwart, M. (1980). A standardized set of 260 pictures: Norms for name agreement, image agreement, familiarity, and visual complexity. Journal of Experimental Psychology: Human Learning and Memory, 6, 174-215.

Stein, M., Dierks, T., Brandeis, D., Wirth, M., Strik, W., \& Koenig, T. (2006). Plasticity in the adult language system: A longitudinal electrophysiological study on second language learning. Neuroimage, 33, 774-783.

Van Petten, C. (1993). A comparison of lexical and sentence-level context effects and their temporal parameters. Language and Cognitive Processes, 8, 485-532.

Van Petten, C. (1995). Words and sentences: Event-related brain potential measures. Psychophysiology, 32, 511-525.

Van Petten, C., \& Luka, B. J. (2006). Neural localization of semantic context effects in electromagnetic and hemodynamic studies. Brain and Language, 97, 279-293.

Vandenberghe, R., Price, C., Wise, R., Josephs, O., \& Frackowiak, R. S. J. (1996). Functional anatomy of a common semantic system for words and pictures. Nature, 383, 254-256.

Wise, R. J., Scott, S. K., Blank, S. C., Mummery, C. J., Murphy, K., \& Warburton, E. A. (2001). Separate neural subsystems within "Wernicke's area." Brain, 124, 83-95.

Young, A. R., Beitchman, J. H., Johnson, C., Douglas, L., Atkinson, L., Escobar, M., et al. (2002). Young adult academic outcomes in a longitudinal sample of early identified language impaired and control children. Journal of Child Psychology and Psychiatry, 43, 635-645.

Yu, C., \& Smith, L. B. (2007). Rapid word learning under uncertainty via cross-situational statistics. Psychological Science, 18, 314-320.

Yu, C., Smith, L. B., Klein, K., \& Shiffrin, R. (2007). Hypothesis testing and associative learning in cross-situational word learning: Are they one and the same? Proceedings of the 29th Annual Meeting of Cognitive Science Society (CogSci 2007), Nashville, TN. 